\title{
Editorial
}

\section{COVID-19 and Children's Rights: Space for Reflection, Tracing the Problems and Facing the Future}

Children all over the world shared similar, but not identical, experiences during the past year. The most common and most noticeable effects of COVID-19 were school closures and lockdowns, where siblings, parents and other household members stayed at home day in and day out. Physical relationships and interactions with friends and relatives were restricted or completely banned for weeks and months. The toll on some children was even greater. Life for children in detention or children with parents in detention was exceptionally hard, as physical contact was banned for months and replaced by 'virtual visits'. Children who share their time between two households, usually following parental separation, could not always move from one home to the other, experiencing disruption of their care and relationships. Regulations in some countries have tried to mitigate this disruption, with different level of success. International border clousres have meant that, for some children, family separation is the new living reality. The children of those who migrate for work or other reasons are no strangers to family separation, but they have been adversely impacted in different ways as illustrated in Kohso and Noor's contribution. Other children have lost their parent(s), grandparent(s) or other family members, and research, from a children's rights perspective, will be needed on the impact that this has had on them.

Life after covid will be different for diverse groups of children. As we write this Editorial, children in some parts of Europe are beginning to return to school after nearly 15 months at home, while for children in New Zealand and Australia lockdowns are a distant memory. In many countries in South America, India and Africa, the end of lockdown is not yet in sight as new 
variants of the virus emerge, confronting children with the prospect of spending many more months at home.

One theme that has been brought into sharp focus by Covid-19 has been children's access to and experiences of justice. Four papers in this volume deal explicitly with different aspects of legal justice, each providing new insights not just into the challenges but the potential benefits of new technologies for advancing and sustaining justice systems (Lynch and Kilkelly; Porter et al; Driscoll and Hutchnison; and Minson and Flynn). Such insights tell us that access to justice should not feel or be 'remote' simply by virtue of the fact that it is being conducted online. Quite the contrary: it should be seen as an opportunity to forge a deeper connection between children and decision-makers; and to provide access to legal advice, representation and participation literally at the push of a button. And that opportunity goes both ways: virtual proceedings potentially offer new, unique insights for judges who get to see more deeply and clearly into the reality of children's physical and relational surroundings in ways that seemed unimaginable before. As one High Court judge noted, in a recent English case:

"As I have observed now, in a number of cases, one of the advantages of "sitting remotely" via video conferencing platforms, is that it is possible for the judge to meet with patients and families in circumstances which seem a long way from the formality of a court room. In the course of the pandemic I have found myself in people's kitchens, living rooms, in care homes and by hospital beds. This unanticipated advantage has permitted greater access to the court."1

But justice is manifested in a much broader range of issues beyond the legal process. COVID-19 has both exposed and compounded an array of social justice concerns, including its disproportionately adverse economic and social impacts on the world's poorest. Health justice - defined by affordable and equitable access to health care, as well as accommodation of and support for more routine, but equally life-limiting physical, and mental health needs - has also been severely tested by the pandemic. Indeed, as Bouah and Sloth-Nielsen, and Adami and Dineen's papers highlight, the pandemic simultaneously exposes and compounds the impacts of poverty and social inequalities at a regional, national and global level. Such issues raise serious questions of the legitimacy and requirements of another take on justice: that of intergenerational justice.

1 University Hospitals Bristol and Weston NHS Foundation Trust v. Godfrey, [2021] EWHC 163 (Fam) per Justice Hayden, para 17. 
The Irish philosopher, Edmund Burke's description of society as '...but a contract between the dead, the living and those yet to be born'2 has particular resonance in the context of CoviD-19. Lockdown has required many of our youngest citizens - those deemed to be least at risk from CoviD-19 infection - to endure educational, social and emotional isolation and dislocation in order to protect the oldest and most vulnerable in society. These hardships are accepted as necessary fulfilment of the social contract, but their effects are likely to be experienced long after the pandemic has abated, prompting questions as to how our future generations will bear the burden for years to come, as the papers by Croke and Verdoot suggest.

Dealing with the economic and social fall-out will likely demand enormous systemic change in the way we fund social care and health systems, and in how we balance the cost of early years services and education with enhanced support for older generations. Past periods of recession have taught us that children tend to fare least well when it comes to public cuts and systemic change. But a true regard for intergenerational justice cautions us against disproportionately burdening our young with the responsibility of absorbing the costs of this pandemic. Any recovery plan must pave the way for our young and future generations; it must nurture a social, economic and natural environment in which our children, and our children's children can thrive.

Children's lives today are very different from their lives pre-Covid and they are likely to continue to change and evolve even as a new, more stable, normal will emerge. Concerns that childhood has disappeared, or radically changed, are not new, and it seems that another chapter in the story of childhoods has now begun. As a children's rights community, we should look closely at these changes and ask whether children's rights should change too and, if so, how and why. Is the set of rights that children have today under the UNCRC still relevant, or should those rights be adapted to meet the challenges and, in many cases, the irreversiable effects of covid? The devastating and disproportionate effects that the First World War had on children, mainly in Europe, led the League of Nations to adopt the Declaration of the Rights of the Child in 1924. Are we witnessing a moment that warrants the adoption of a new global instrument, maybe this time with children participating in the drafting process in a meaningful way? This proposal is not risk free, as there is a good chance that adults with competing agendas will seize - perhaps even exploit COVID-19 to scale back some or all of the rights and protections available to children in the name of public health or economic stability. Or maybe we need a new

2 EDMUND BURKE, "Reflections on the Revolution in France," 1790, The Works of the Right Honorable Edmund Burke, vol. 3, p. 359 (1899). 
and robust optional protocol about the utility and usage of the Convention in a post-Covid world, or a General Comment that will provide a road map for States and other duty bearers in protecting the rights of children in times of emergencies and crisis, taking into consideration intersectionality and the multiple varied experiences and impacts that covid has had for children, as Bouah and Sloth Nilsen suggest in their article. Local and regional instruments might more fittingly capture local cultures and norms, providing a better and more effective way forward.

The move to online life also warrants changes in the ways we engage across our research community. It has opened the door to many collaborations that previously were not feasible due to travel costs and a culture that required physical presence for participation. Now we have the opportunity to create, develop and expand more equitable relationships with scholars from the global south, an agenda that the Journal has already set but intends to continue to promote.

The pandemic has also fundamentally shaped whether and how some of our research community undertake their work. In the last editorial, we highlighted the significant personal impact on some of our research community, in particular the women and carers who have been disproportionately affected. The adverse impacts on research progress also vary by discipline and methodological approach. Those whose research is desk-based, for example those undertaking doctrinal legal analysis, will have been impacted minimally, from the perspective of research process. For some, such as ethnographers and those whose fieldwork is abroad, whole research agendas may have been stalled. For others, notably those who undertake qualitative research, the impacts may have been profound.

Many of our community conduct direct research with children, accessing them through schools and/or youth groups. With the latter closed, access has for some been impossible. Those who were already experienced in online approaches, were in a position to engage quickly. For others, it has meant rethinking research methodologies, developing new skills and embracing new approaches to surveys, interviews and focus groups. However, there are few with experience of in-person interviews or focus groups who would happily swap permanently to the online alternatives given a choice. This is arguably especially true for research with children where it is important to create a relationship of trust and a research space where they feel comfortable and empowered. When children are at home, the challenge in creating and maintinig this is a challenge, if the environment is neither safe nor comfortable, and if the resaerch has the potential to put the children in an uncomfortable situation vis-à-vis other household members, especially their paretns. 
Some of the learning and skills will be taken forward: as Lundy et al and the Covidunderig study demonstrate, the use of online tools has enabled access to children and young people right across the world, extending the reach of the project. However, as elsewhere, it has exposed some faultlines, this time in knowledge generation, creating a new category of the seldom heard - those without access to reliable electiricty connectivity, digital devices and/or the internet. Moreover, the challenge in reaching children during the pandemic is not restricted to children experiencing social and economic disadvantage. The reliance on digital methods also excludes many younger children and some children with disabilities. There will be gaps in our knowledge that will need to be addressed in the years to come. Croke et al's paper, for example, underscores the need for rights-based research on all aspects of children's lives, including their health.

The pandemic has also led to a rethink in the ethics of research with children and young people. Within childhood research, a key issue has been ensuring that children's personal data is protected online. This has led many of us to question the platforms that we use for research and probe where they store the data that we generate. This challenge is helped by the timely publication of the UN Committee on the Rights of the Child's General Comment No. 25 on children's rights in the digital environment in March 2021, which include requires states to ensure that the rights of children to privacy, freedom of thought and opinion will be proteted when utilizing the digital enviroment, and that children will participate in the process of putting together legislative, administrative and other measures to achieve this objective (UN, 2021, para 18). Our research community can learn from this too.

\author{
Noam Peleg \\ Book reviews editor \\ Laura Lundy and Helen Stalford \\ Editors
}

